\title{
Physiological predictors of survival during high-frequency oscillatory ventilation in adults with acute respiratory distress syndrome
}

\author{
Luigi Camporota*, Tony Sherry, John Smith, Katie Lei, Angela McLuckie and Richard Beale
}

\begin{abstract}
Introduction: Data that provide clinical criteria for the identification of patients likely to respond to high-frequency oscillatory ventilation (HFOV) are scarce. Our aim was to describe physiological predictors of survival during HFOV in adults with severe acute respiratory distress syndrome (ARDS) admitted to a respiratory failure center in the United Kingdom.

Methods: Electronic records of 102 adults treated with HFOV were reviewed retrospectively. We used logistic regression and receiving-operator characteristics curve to test associations with oxygenation and mortality.

Results: Patients had severe ARDS with a mean (SD) Murray's score of 2.98 (0.7). Partial pressure of oxygen in arterial blood to fraction of inspired oxygen $\left(\mathrm{PaO}_{2} / \mathrm{FiO}_{2}\right)$ ratio and oxygenation index improved only in survivors. The earliest time point at which the two groups differed was at three hours after commencing HFOV. An improvement of $>38 \%$ in $\mathrm{PaO}_{2} / \mathrm{FiO}_{2}$ occurring at any time within the first 72 hours, was the best predictor of survival at 30 days (area under the curve (AUC) of 0.83 , sensitivity $93 \%$, specificity $78 \%$ and a positive likelihood ratio (LR) of 4.3). These patients also had a 3.5 fold greater reduction in partial pressure of carbon dioxide in arterial blood $\left(\mathrm{PaCO}_{2}\right)$. Multivariate analysis showed that HFOV was more effective in younger patients, when instituted early, and in patients with milder respiratory acidosis.

Conclusions: HFOV is effective in improving oxygenation in adults with ARDS, particularly when instituted early. Changes in $\mathrm{PaO}_{2} / \mathrm{FiO}_{2}$ during the first three hours of HFOV can identify those patients more likely to survive.
\end{abstract}

\section{Introduction}

Patients with acute respiratory distress syndrome (ARDS) exhibit a highly inhomogeneous, compliancedependent distribution of regional ventilation during conventional mechanical ventilation (CMV) [1]. Consequently, CMV can lead to further lung injury through tidal hyperinflation and shear stress injury, even when it is administered according to a 'lung protective strategy' that limits tidal volumes and plateau pressure [2], and employs recruitment maneuvers to maximize the proportion of aerated alveolar tissue [1]. High-frequency oscillatory ventilation (HFOV) can theoretically offer effective lung protective ventilation by delivering very

\footnotetext{
* Correspondence: luigi.camporota@gstt.nhs.uk

Division of Asthma, Allergy and Lung Biology, King's College London and Department of Adult Critical Care, Guy's and St Thomas' NHS Foundation Trust, King's Health Partners, St Thomas' Hospital, $1^{\text {st }}$ Floor East Wing, Lambeth Palace Road, London, SE1 7EH, UK
}

low tidal volumes ( 1 to $3 \mathrm{~mL} \mathrm{Kg}^{-1}$ ) around a fixed mean airway pressure at frequencies of 5 to $12 \mathrm{~Hz}$ (lower frequencies are used in adults). At high respiratory frequencies, the short inspiratory time results in a distribution of ventilation which, compared to mechanical ventilation at conventional breathing rates, is more homogeneous and less dependent on the distribution of regional lung compliance $[3,4]$. This results in the protection of the recruited lung (with greater compliance) from excessive cyclic variations in alveolar pressure. In addition, if the continuous distending pressure (CDP) is optimized following a stepwise recruitment maneuver, the more compliant lung regions are less susceptible to static hyperinflation $[3,5,6]$, thereby reducing lung strain and ventilation-induced inflammation $[7,8]$.

HFOV improves gas exchange and reduces lung injury in animal models of ARDS [9-11] and in human neonatal and pediatric populations [12-15]. In adults the

\section{Biomed Central}


effects of HFOV are largely limited to observational studies [16-24] and two randomized trials [25,26]. Overall these studies show that HFOV might improve gas exchange and survival. However, data that provide clinical criteria for identification of patients likely to benefit from HFOV are scarce $[23,24]$. Large studies outside North America, utilizing different protocols are lacking, although the results of two multicenter clinical trials in the UK and Canada (OSCAR and OSCILLATE trials) are awaited $[16,27,28]$.

In this study we aim to describe potential physiological predictors of survival during HFOV in adults with severe ARDS admitted to an advanced respiratory failure center in the United Kingdom.

\section{Materials and methods Patients}

This was a single center observational study of patients with ARDS admitted to the Adult Intensive Care Service at Guy's and St Thomas' Hospital in London between 1998 and 2002. We included patients who were treated with HFOV because of severe gas exchange impairments while on CMV. Medical records and physiological data before, during and after HFOV were retrieved from our ICU electronic patient record (Intellivue Clinical Information Portfolio, Philips Medical Systems UK Limited). Patients' demographic data, hemodynamic variables, oxygenation and ventilator settings were recorded while on CMV prior to HFOV, during HFOV, prior to discontinuation of HFOV and on recommencement of CMV. Oxygenation index $\left(\mathrm{OI}=\left(\mathrm{FiO}_{2} \mathrm{CDP} 100\right) / \mathrm{PaO}_{2}\right)$ and partial pressure of oxygen in arterial blood to fraction of inspired oxygen $\left(\mathrm{PaO}_{2} / \mathrm{FiO}_{2}\right)$ ratio were calculated at the same intervals. Acute Physiology and Chronic Health Evaluation (APACHE II) and Murray lung injury severity score (which combines degree of lung infiltration on chest $\times$ ray, lung compliance, $\mathrm{PaO}_{2} / \mathrm{FiO}_{2}$ and positive end expiratory pressure (PEEP)) [29] at admission and on commencement of HFOV were determined (with a blinded and independent radiologist scoring the chest $\mathrm{x}$ ray appearance). Hemodynamic data were obtained using cardiac output monitors PiCCOplus (Pulsion, Munich, Germany, Software version 7.0 non USA), or a LiDCO (LiDCO Ltd, London, UK). This study was considered by the National Research Ethics Service as 'service evaluation' and therefore did not require Research Ethics Committee review [30].

\section{Ventilator settings and study protocol}

All patients were ventilated with pressure-controlled ventilation before starting HFOV, using a lung protective strategy [31,32]. Patients were considered for HFOV if $\mathrm{SaO}_{2}<88 \% / \mathrm{PaO}_{2}<60 \mathrm{mmHg}, \mathrm{FiO}_{2}>0.6$ and $\mathrm{pH}<7.2$.
HFOV was delivered using an adult high-frequency oscillatory ventilator (3100B, Viasys (CareFusion), Yorba Linda, CA, USA). All patients were initiated onto HFOV using the following settings: a $\mathrm{FiO}_{2}$ of 1.0, a frequency of 4 to $6 \mathrm{~Hz}$, inspiratory time of 33\%, a bias flow of 30 to $40 \mathrm{Lmin}^{-1}$, a CDP set 3 to $5 \mathrm{cmH}_{2} \mathrm{O}$ above the CDP during CMV and a Power to obtain transmitted oscillation ('wiggles') up to the level of mid-thigh. The power dial determines the amount of power that drives the oscillator piston to and fro. The Power control is a 10turn locking dial, electrical potentiometer covering the power range of 0 to $100 \%$. The effect of this control is to change the displacement of the oscillator piston and hence to determine the oscillatory pressure $\Delta \mathrm{P}$. The Power setting interacts with the pulmonary artery wedge (Paw) and the conditions existing within the circuit to produce the resultant $\Delta \mathrm{P}[33]$.

On starting HFOV, patients underwent a standardized slow recruitment maneuver (SRM), which represents the standard of care for patients receiving HFOV in this Institution. The SRM is derived from the maneuver included in the original MOAT Study protocol [34]. The SRM was performed by a stepwise increase in CDP by increments of $3 \mathrm{cmH}_{2} \mathrm{O}$ every 10 minutes, starting from the CDP on $\mathrm{CMV}+3$ to $5 \mathrm{cmH}_{2} \mathrm{O}$, up to $50 \mathrm{cmH}_{2} \mathrm{O}$. SRM was interrupted if the mean arterial pressure fell below $55 \mathrm{mmHg}$ or if desaturations (SpO2<85\%) or arrhythmias occurred. Subsequently, CDP was reduced by $2 \mathrm{cmH}_{2} \mathrm{O}$ every 5 minutes. Arterial blood gases were taken every 10 minutes (every step during the incremental CDP, phase, and every two steps of the decremental CDP, phase). The 'optimal' CDP was established as the lowest CDP that achieved the most favorable combination between the highest $\mathrm{PaO}_{2}$ and/or lowest $\mathrm{PaCO}_{2}$, while maintaining the $\mathrm{FiO}_{2}$ constant at 1.0.

The protocol for the adjustment of HFOV was published previously [25]. A reduction of CDP was initiated when the $\mathrm{FiO}_{2}$ was $\leq 0.5$. Once CDP $\leq 20$ to $22 \mathrm{cmH}_{2} \mathrm{O}$ was achieved on a $\mathrm{FiO}_{2}$ of 0.4 , the patients returned to CMV. CMV was restarted in the pressure-control mode with CDP close to the CDP on HFOV, plateau pressures $<28 \mathrm{cmH}_{2} \mathrm{O}$ and PEEP adjusted to a tidal volume of $6 \mathrm{mLKg}^{-1}$ of predicted body weight.

\section{Outcome measures}

The primary outcome measures were: improvement in $\mathrm{PaO}_{2} / \mathrm{FiO}_{2}$ and $\mathrm{OI}$ and identification of physiological variables associated with 30-day survival.

To stratify patients we used an empirical score generated from the available data that was solely designed to give a pragmatic quantification of disease severity and not intended to have diagnostic or prognostic value. The score included $\mathrm{PaO}_{2} / \mathrm{FiO}_{2}$, basal $\mathrm{PaCO}_{2}$, respiratory 
system compliance, minute ventilation and mean airway pressure. This score was used as a dichotomous variable to separate patients with a more severe index of disease (score $>50$ th percentile) from those with a less severe index of disease (score $<50$ th percentile).

\section{Statistical analysis}

Distribution of baseline variables was assessed using the Kolmogorov-Smirnov test. Differences in baseline variables between survivors and non-survivors were compared using the two-tailed t-test or Mann-Withney U test for continuous data, and $\chi^{2}$ or the Fisher test for qualitative data. Differences in physiological variables over time between the two outcome groups were evaluated using repeated-measure analysis of variance (ANOVA). The Friedman test and Dunn's post-hoc analysis was performed for non-normally distributed data. Multiple regression analysis and analysis of co-variance (ANCOVA) were used to test the effect of various physiological variables on oxygenation indices. Continuous outcome variables were corrected for confounding variables at baseline. Post hoc analyses were performed using Bonferrroni's correction. Variables associated with mortality in an analysis of covariance were entered in a multivariate logistic backward-likelihood ratio regression analysis, to identify predictors of mortality at different end-points. The Hosmer-Lemeshow goodness-of-fit test was used to test the validity of the model. Receiveroperating characteristic (ROC) curves were plotted to determine the best predictor of survival. The value with the best sensitivity, specificity and positive predictive value was selected as the cut-off point to predict survival.

Analyses were performed using SPSS software (version 12; SPSS, Chicago, IL, USA) and MediCalc (Mariakerke, Belgium) for ROC curve analysis. Two-tailed tests for significance were used, and a $P$ value less than 0.05 was considered statistically significant.

\section{Results}

We report the results on 102 consecutive ARDS patients who received HFOV. The median (IQR) duration of ARDS prior to HFOV was 48 hours (24 to 120 hours). The median (IQR) duration of CMV prior to HFOV was 45 hours (9 to 138 hours). Table 1 presents the baseline patient demographics, physiological variables and severity scores at study entry. Table 2 summarizes patients' outcome and complications from HFOV.

Overall, HFOV was well tolerated with low incidence of new or worsening pneumothoraces, pneumomediastinum or subcutaneous emphysema (2\%) and hemodynamic compromise. Two patients (1.96\%) suffered profound hypotension during HFOV.
Table 1 Patient characteristics at study entry

\begin{tabular}{|c|c|}
\hline Variable & \\
\hline \multicolumn{2}{|l|}{ Patient characteristics } \\
\hline Patients, number & 102 \\
\hline Age, years & $50.8 \pm 15.9$ \\
\hline Gender, \% male & 67.6 \\
\hline Actual body weight, $\mathrm{Kg}$ & $75.7 \pm 21.24$ \\
\hline APACHEIl prior HFOV & $24.1 \pm 8.0$ \\
\hline Murray Score & $2.98 \pm 0.7$ \\
\hline Duration ARDS prior HFOV, hours median (IQR) & $48(24$ to 120$)$ \\
\hline Duration CMV prior HFOV, hours median (IQR) & 45 (9 to 138$)$ \\
\hline \multicolumn{2}{|l|}{ Gas exchange on CMV pre-HFOV } \\
\hline $\mathrm{PaO}_{2}, \mathrm{mmHg}$ & $74.2 \pm 21$ \\
\hline $\mathrm{PaCO}_{2}, \mathrm{mmHg}$ & $57.6 \pm 18.7$ \\
\hline $\mathrm{PaO}_{2} / \mathrm{FiO}_{2}, \mathrm{mmHg}$ & $93.8 \pm 38.3$ \\
\hline $\mathrm{SaO}_{2}, \%$ & $88.6 \pm 11.99$ \\
\hline $\mathrm{Ol}, \mathrm{cmH}_{2} \cdot \mathrm{mmHg}^{-1}$ & $27 \pm 13.4$ \\
\hline $\mathrm{pH}$ & $7.26 \pm 0.14$ \\
\hline \multicolumn{2}{|l|}{ Respiratory variables on CMV pre-HFOV } \\
\hline $\mathrm{PIP}, \mathrm{cmH}_{2} \mathrm{O}$ & $32.1 \pm 5.67$ \\
\hline PEEP, $\mathrm{cmH}_{2} \mathrm{O}$ & $12.4 \pm 3.7$ \\
\hline $\mathrm{CDP}, \mathrm{cmH}_{2} \mathrm{O}$ & $21.6 \pm 4.97$ \\
\hline Compliance & 26.4(19.9 to 36.3$)$ \\
\hline Minute ventilation, $L \mathrm{~min}^{-1}$ & 10.4 (8.5 to 12.6$)$ \\
\hline Respiratory rate & $20.9 \pm 5.1$ \\
\hline Tidal volume on $\mathrm{CMV}, \mathrm{mL}$ & 551 (421.7 to 620) \\
\hline \multicolumn{2}{|l|}{ Hemodynamics on CMV pre-HFOV } \\
\hline PAWP, $\mathrm{cmH}_{2} \mathrm{O}$ & $16.8 \pm 7.1$ \\
\hline Cardiac Output, L.min ${ }^{-1}$ & $5.95 \pm 1.7$ \\
\hline \multicolumn{2}{|l|}{ Etiology of ARDS } \\
\hline Sepsis & 69 \\
\hline Pulmonary infection & 13 \\
\hline Trauma & 3 \\
\hline Aspiration & 2 \\
\hline Pancreatitis & 2 \\
\hline Drug-induced & 1 \\
\hline Other & 12 \\
\hline
\end{tabular}

Data are presented as absolute number, \% or mean \pm standard deviation (SD) unless otherwise indicated. CDP, continuous distending pressure; CMV, conventional mechanical ventilation; $\mathrm{CO}$, cardiac output; $\mathrm{FiO}_{2}$, fraction of inspired oxygen; HFOV, high-frequency oscillatory ventilation; PAWP, pulmonary artery wedge pressure; PEEP, positive end-expiratory pressure; PIP, peak inspiratory pressure; OI, oxygenation index $\left(\mathrm{OI}=\left(\mathrm{FiO}_{2} \cdot \mathrm{CDP} \cdot 100\right) / \mathrm{PaO}_{2}\right)$.

\section{Effects of HFOV on gas exchange}

During the first 72 hours of HFOV, $\mathrm{PaO}_{2} / \mathrm{FiO}_{2}$ improved significantly from baseline only in survivors (Figure 1a). The earliest time-point at which $\mathrm{PaO}_{2} / \mathrm{FiO}_{2}$ was statistically different from baseline in the survivor group was at three hours of HFOV $(P<0.05)$ (Figure 1a). The improvement in $\mathrm{PaO}_{2} / \mathrm{FiO}_{2}$ was not determined by the level of CDP (Figure 1b) with mean CDP \pm SD of $33.9 \pm 5.4 \mathrm{cmH}_{2} \mathrm{O}$ versus $32.0 \pm 7.05 \mathrm{cmH}_{2} \mathrm{O}(P=0.08)$, respectively, for survivors and non-survivors. The 
Table 2 Patient outcomes and complications

\begin{tabular}{lc}
\hline Variable & \\
\hline Airleak & \\
Air Leak before HFOV & $22 / 102(21.6 \%)$ \\
Persistent air Leak during HFOV & $5 / 22(22.7 \%)$ \\
$\quad$ New air leak during HFOV & $2 / 80(2.5 \%)$ \\
Co-treatment & \\
(Some patients received more than one co-treatment) & \\
$\quad$ Nitric oxide & $21 / 102(20.6 \%)$ \\
MARS & $1 / 102(0.98 \%)$ \\
Steroids & $19 / 102(18.6 \%)$ \\
Prone position & $20 / 102(19.6 \%)$ \\
rhAPC & $3 / 102(2.9 \%)$ \\
None & $56 / 102(54.9 \%)$ \\
Mortality & \\
Post HFOV & $49 / 102(48 \%)$ \\
ICU discharge & $62 / 102(60.8 \%)$ \\
30-day & $57 / 102(55.9 \%)$ \\
Cause of death at 30-days & \\
Withdrawal of treatment & $22 / 57(38.6 \%)$ \\
$>2$ organ failure & $20 / 57(35.1 \%)$ \\
Cardiac arrhythmia & $6 / 57(10.5 \%)$ \\
Refractory hypoxia & $4 / 57(7 \%)$ \\
Sepsis & $3 / 57(5.3 \%)$ \\
Profound hypotension & $2 / 57(3.5 \%)$ \\
\hline
\end{tabular}

HFOV, high-frequency oscillatory ventilation; MARS, Molecular Adsorbents Recirculation System; rhAPC, recombinant human Activated Protein C (Drotrecogin alfa activated, Xigris).

change in $\mathrm{PaO}_{2} / \mathrm{FiO}_{2}$ remained significantly different $(P=0.03)$ between the two outcome groups after adjusting for baseline confounding factors such as age, $\mathrm{PaO}_{2} /$ $\mathrm{FiO}_{2}$ and CDP. The independence from CDP during HFOV was further demonstrated by the divergence of OI between the two groups and the fact that OI improved significantly over the first 72 hours only in survivors (Figure 1c). Analysis of ROC curves identified an improvement of $38 \%$ in $\mathrm{PaO}_{2} / \mathrm{FiO}_{2}$ and an improvement of $>22 \%$ in the OI during the first 72 hours of HFOV as the criteria with the best positive predictive values for survival, with respective sensitivities of $93.3 \%$ and $87 \%$, specificities of $78.3 \%$ and $78.0 \%$ and positive likelihood ratios of 4.29 and 3.96. Change in $\mathrm{PaO}_{2} / \mathrm{FiO}_{2}$ was a better indicator of survival compared with the change in OI, with an area under the ROC curve of 0.83 ( $95 \% \mathrm{CI}, 0.71$ to 0.92 ) versus 0.69 (95\% CI 0.55 to 0.8 ) ( $P=0.039$, pair-wise comparison of ROC curves).

Multivariate logistic regression analysis identified the following four independent predictive factors of mortality at 30 days: 1 ) days with ARDS prior to HFOV (OR $1.5,95 \%$ CI 1.08 to $1.92 ; P=0.01)$; 2) improvement in $\mathrm{PaO}_{2} / \mathrm{FiO}_{2}$ in the first 72 hours (OR $0.8,95 \% \mathrm{CI} 0.77$ to $0.9 ; P<0.001$ ), 3) age (OR 1.1, $95 \%$ CI 1.02 to $1.14 ; P$ $=0.03)$; and 4$)$ pre-HFOV pH (OR 0.8, $95 \%$ CI 0.7 to


Figure 1 Differences in $\mathrm{PaO}_{2} / \mathrm{FiO}_{2}$ ratio, CDP and $\mathrm{Ol}$ in survivors (open circles) and non-survivors (filled circles). X-axis indicates time (hours) on HFOV. Baseline is the time on CMV immediately preceding the change to HFOV. 'Last' is the last measurement on HFOV prior to returning to CMV. A: Differences $\mathrm{PaO}_{2} / \mathrm{FiO}_{2}$ ratio over time between survivors (open circles) versus non-survivors (filled circles). B: Trends of change in CDP between survivors and non-survivors. Data are displayed as mean and error bars represent SEM at each time-point. The number of patients (survivors - $S$; and non-survivors -NS) at different time- points were: at baseline ( $S, n=45 ; N S, n=57) ; 12$ hours $(S, n=44 ; N S, n=38)$; 24 hours (,$n=39 ; N S, n=28) ; 48$ hours (,$n=31 ; N S, n=24) ; 72$ hours(S, $n=25$; NS, $n=19) .{ }^{*}=P<0.01$ - comparisons at each timepoint versus baseline. CDP, continuous distending pressure; $\mathrm{CMV}$, conventional mechanical ventilation; $\mathrm{FiO}_{2}$, fraction of inspired oxygen; HFOV, high-frequency oscillatory ventilation; SEM, standard error of the mean. 
0.9; $P=0.004)$. The change in $\mathrm{PaO}_{2} / \mathrm{FiO}_{2}$ and $\mathrm{OI}$ after three hours of HFOV was the earliest time point to predict outcome.

There was an interaction between change in $\mathrm{PaO}_{2} /$ $\mathrm{FiO}_{2}$ and the etiology of ARDS, with a greater change in $\mathrm{PaO}_{2} / \mathrm{FiO}_{2}$ for patients with extra-pulmonary ARDS, independent of baseline $\mathrm{PaO}_{2} / \mathrm{FiO}_{2}$, which may reflect the different degree of lung recruitability.

\section{Effects of HFOV on $\mathrm{PaCO}_{2}$}

Survivors had a lower baseline $\mathrm{PaCO}_{2}$ with a median (IQR) of $47 \mathrm{mmHg}$ (38.6 to $62.2 \mathrm{mmHg}$ ) versus 58 $\mathrm{mmHg}(47.5$ to $72.3 \mathrm{mmHg})(P=0.008)$ and lower $\mathrm{PaCO}_{2}$ throughout HFOV treatment $(P<0.001)$ and on return to $\mathrm{CMV}$ (Table 3). Overall, $\mathrm{PaCO}_{2}$ decreased significantly throughout the duration of $\operatorname{HFOV}(P=0.001$, repeated measure ANOVA) and, at each time-point, $\mathrm{PaCO}_{2}$ was significantly lower than baseline in both groups $(P<0.001)$ (Figure 2a).

There was a trend towards greater reduction in $\mathrm{PaCO}_{2}$ in 'responders' as defined on the ROC curve by an increase in $\mathrm{PaO}_{2} / \mathrm{FiO}_{2}$ ratio of $>38 \%$ compared to 'nonresponders' (increase in $\mathrm{PaO}_{2} / \mathrm{FiO}_{2}$ ratio of $<38 \%$ ), with a median per cent change (IQR) of $-17.4 \%(-33.4$ to $5.48)$ versus $-4.9 \%(-19.8$ to 11.9$)(P=0.07)$ (Figure $2 b)$. Furthermore, patients with a worse empirical disease severity score showed a more rapid clearance of $\mathrm{PaCO}_{2}$ during the first 12 hours of HFOV (Figure 2c) despite similar settings of frequency, amplitude and power (Figure 3). The absolute $\mathrm{PaCO}_{2}$ remained higher in the more severe group. This result may suggest that patients with more severe disease have a greater proportion of recruitable lung and an increase in alveolar ventilation following HFOV. Overall, patients with lower respiratory system compliance had a trend towards a greater change in $\mathrm{PaCO}_{2}$ post-SRM (-20.5\% versus $\left.-2.4 \% ; P=0.08\right)$, and there was a correlation between change in $\mathrm{PaCO}_{2}$ post-SRM and change in compliance post-HFOV $\left(\mathrm{r}^{2}=\right.$ $0.6 ; P=0.04)$.

\section{Discussion}

This study aimed to identify potential predictors of survival in patients with severe ARDS who received HFOV after failing lung-protective CMV. The key results of our study are that: 1) an early improvement in $\mathrm{PaO}_{2} /$ $\mathrm{FiO}_{2}$ ratio is a predictor of survival at 30 days; 2) patients with more severe disease and lower respiratory system compliance pre-HFOV show greater $\mathrm{CO}_{2}$ clearance; and 3) if there is no improvement in gas exchange within three hours, patients can be considered to have
Table 3 Patient characteristics at $\mathbf{3 0}$ days: comparison of survivors versus non-survivors

\begin{tabular}{|c|c|c|c|c|c|}
\hline \multirow[t]{2}{*}{ Variable } & \multicolumn{2}{|c|}{$\begin{array}{c}\text { Survivors } \\
\text { (number = } \\
45 \text { ) }\end{array}$} & \multicolumn{2}{|c|}{$\begin{array}{c}\text { Non- } \\
\text { survivors } \\
\text { (number = } \\
57 \text { ) }\end{array}$} & \multirow[b]{2}{*}{$\begin{array}{c}P \\
\text { value }\end{array}$} \\
\hline & Mean & SD & Mean & SD & \\
\hline \multicolumn{6}{|l|}{ Demographics } \\
\hline Age, years & 45.7 & 16.2 & 54.9 & 14.6 & 0.003 \\
\hline Weight, Kg & 75.8 & 22.7 & 75.6 & 20.2 & ns \\
\hline APACHE II (prior to HFOV) & 22.9 & 6.52 & 24.98 & 8.96 & ns \\
\hline Murray Score & 3.0 & 0.62 & 2.9 & 0.77 & ns \\
\hline $\begin{array}{l}\text { Duration ARDS prior to HFOV, } \\
\text { days }\end{array}$ & 2.9 & 3.6 & 4.5 & 4.7 & 0.015 \\
\hline $\begin{array}{l}\text { Duration CMV prior to HFOV, } \\
\text { hours }\end{array}$ & 88.9 & 131.9 & 90.4 & 105.9 & ns \\
\hline \multicolumn{6}{|l|}{ Gas exchange indices } \\
\hline $\begin{array}{l}\mathrm{PaO}_{2} / \mathrm{FiO}_{2} \text { prior to HFOV, } \\
\mathrm{mmHg}\end{array}$ & 96.8 & 38.8 & 90.8 & 38.3 & ns \\
\hline $\begin{array}{l}\mathrm{PaO}_{2} / \mathrm{FiO}_{2} \text { return to } \mathrm{CMV}, \\
\mathrm{mmHg}\end{array}$ & 211.5 & 96.0 & 129.0 & 70.5 & 0.001 \\
\hline$\Delta \mathrm{PaO}_{2} / \mathrm{FiO}_{2}$ & 111.0 & 89.3 & 26.7 & 63.0 & $<0.01$ \\
\hline $\mathrm{PaCO}_{2}$ prior to $\mathrm{HFOV}, \mathrm{mmHg}$ & 54.0 & 20.8 & 60.8 & 17.0 & ns \\
\hline $\mathrm{PaCO}_{2}$ return to $\mathrm{CMV}, \mathrm{mmHg}$ & 50.3 & 17.3 & 81.8 & 97.4 & 0.049 \\
\hline $\begin{array}{l}\text { Ol prior } \mathrm{HFOV}, \mathrm{cmH}_{2} \mathrm{O} \\
\mathrm{mmHg}^{-1}\end{array}$ & 26.1 & 13.4 & 27.6 & 13.4 & ns \\
\hline $\begin{array}{l}\text { Ol return to } \mathrm{CMV}, \mathrm{cmH}_{2} \mathrm{O} \text {. } \\
\mathrm{mmHg}^{-1}\end{array}$ & 10.1 & 6.6 & 21.8 & 19.1 & 0.01 \\
\hline Max $\mathrm{PaCO}_{2}, \mathrm{mmHg}$ & 55.5 & 10.6 & 66.7 & 18.8 & $<0.01$ \\
\hline Min $\mathrm{PaCO}_{2}, \mathrm{mmHg}$ & 36.0 & 6.7 & 47.9 & 16.0 & $<0.01$ \\
\hline $\mathrm{pH}$ prior to HFOV & 7.3 & 0.14 & 7.23 & 0.12 & $<0.01$ \\
\hline $\mathrm{pH}$ return to $\mathrm{CMV}$ & 7.4 & 0.1 & 7.27 & 0.1 & $<0.01$ \\
\hline \multicolumn{6}{|l|}{ Hemodynamic indices } \\
\hline MAP prior to HFOV, mmHg & 76.3 & 15.4 & 75.1 & 12.9 & ns \\
\hline MAP return to $C M V, m m H g$ & 82.9 & 14.6 & 77.0 & 20.9 & ns \\
\hline $\mathrm{CO}$ prior to HFOV, $\mathrm{L} \cdot \mathrm{min}^{-1}$ & 6.1 & 2.0 & 5.8 & 1.5 & ns \\
\hline $\mathrm{CO}$ return to $C M V, L \cdot \mathrm{min}^{-1}$ & 5.9 & 1.3 & 6.1 & 0.5 & ns \\
\hline \multicolumn{6}{|l|}{ Ventilator Indices } \\
\hline Vt prior to HFOV, $\mathrm{mL} \cdot \mathrm{Kg}^{-1}$ & 7.4 & 2.4 & 6.9 & 2.2 & ns \\
\hline Vt return to $C M V, m L \cdot \mathrm{Kg}^{-1}$ & 6.9 & 2.1 & 6.8 & 1.9 & ns \\
\hline PIP prior to $\mathrm{HFOV}, \mathrm{cmH}_{2} \mathrm{O}$ & 31.8 & 6.2 & 32.3 & 5.2 & ns \\
\hline $\mathrm{PIP}$ return to $\mathrm{CMV}, \mathrm{cmH}_{2} \mathrm{O}$ & 28.5 & 5.2 & 30.3 & 5.98 & ns \\
\hline PEEP prior to $\mathrm{HFOV}, \mathrm{cmH}_{2} \mathrm{O}$ & 12.9 & 4.0 & 12.1 & 3.4 & ns \\
\hline PEEP return to $\mathrm{CMV}, \mathrm{cmH}_{2} \mathrm{O}$ & 10.5 & 2.7 & 10.8 & 3.3 & ns \\
\hline $\mathrm{CDP}$ prior to $\mathrm{HFOV}, \mathrm{cmH}_{2} \mathrm{O}$ & 21.8 & 5.7 & 21.4 & 4.3 & ns \\
\hline $\mathrm{CDP}$ return to $\mathrm{CMV}, \mathrm{cmH}_{2} \mathrm{O}$ & 17.5 & 4.5 & 20.7 & 5.9 & 0.02 \\
\hline$\triangle \mathrm{CDP}, \mathrm{cmH}_{2} \mathrm{O}$ & -3.9 & 6.5 & -0.57 & 4.6 & 0.03 \\
\hline
\end{tabular}

$\mathrm{CDP}$, continuous distending pressure; CMV, conventional mechanical ventilation; $\mathrm{CO}$, cardiac output; $\mathrm{FiO}_{2}$, fraction of inspired oxygen; HFOV, highfrequency oscillatory ventilation; Ol, Oxygenation Index $\left(\mathrm{OI}=\left(\mathrm{FiO}_{2} \cdot \mathrm{CDP} \cdot 100\right) /\right.$ $\mathrm{PaO}_{2}$ ); PAWP, pulmonary artery wedge pressure; $\mathrm{PEEP}$, positive end-expiratory pressure; PIP, peak inspiratory pressure; $\mathrm{Vt}$, tidal volume; = change post-HFOV to pre-HFOV. 
A
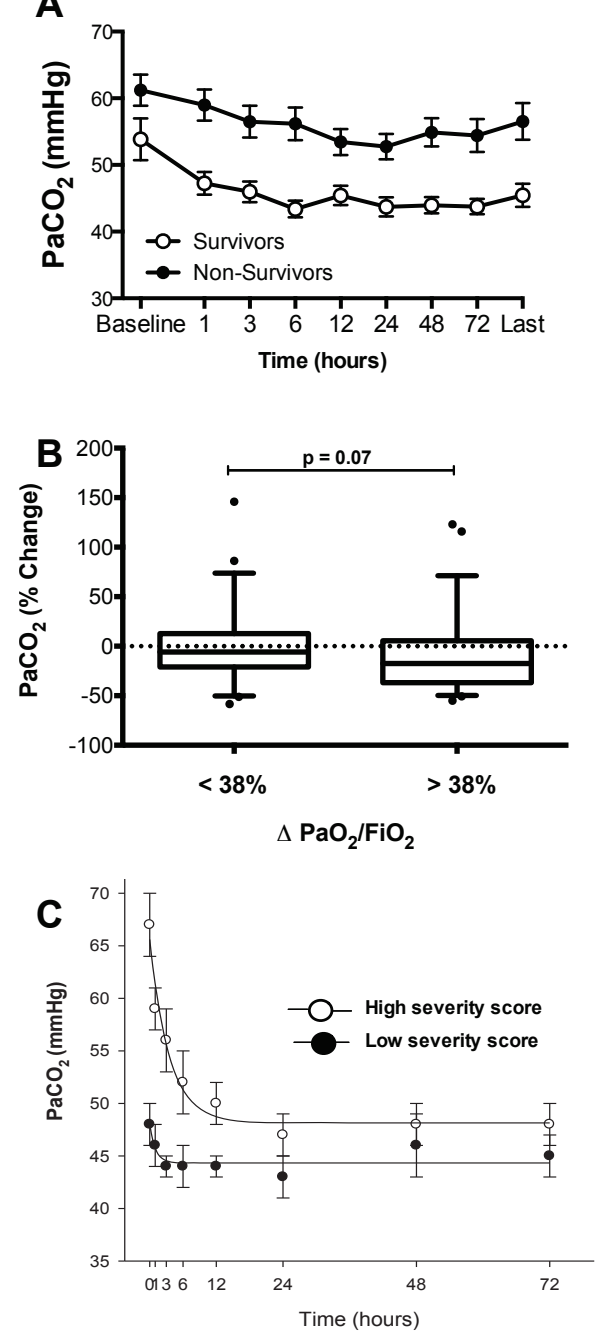

Figure 2 Changes in $\mathrm{PaCO} 2$ based on survival status, response to HFOV and disease severity. A: Differences in $\mathrm{PaCO}_{2}$ in survivors (open circles) and non-survivors (filled circles) over 72 hours of HFOV. X-axis indicates time (hours) on HFOV. Time 0 is the time on CMV immediately preceding the change to HFOV. 'Last' is the last measurement on HFOV prior to returning to CMV. There was no difference in the trend of change in $\mathrm{PaCO}_{2}$ between the two outcome groups. Data are displayed as mean and error bars represent SEM at each time-point. B: Patients were subdivided into two groups (responders and non-responders) based on the analysis of the ROC curve. They were considered responders if their $\mathrm{PaO}_{2}$ / $\mathrm{FiO}_{2}$ ratio improved $>38 \%$ from baseline. Responders show a trend towards better $\mathrm{CO}_{2}$ clearance $(P=0.07)$. Data are displayed as mean and error bars represent SEM. C: Patients were subdivided into two groups based on disease severity. Patients with more severe disease (open circles) have a greater clearance in $\mathrm{PaCO}_{2}$. The number of patients (Survivors - $\mathrm{S}$; and non-survivors -NS) at different timepoints after initiating HFOV were: at baseline (S, $n=45 ; \mathrm{NS}, n=57)$; 12 hours (,$n=44$; NS, $n=38$ ); 24 hours (S, $n=39$; NS, $n=28) ; 48$ hours (S, $n=31$; NS, $n=24) ; 72$ hours (,$n=25 ; N S, n=19)$. CMV, conventional mechanical ventilation; $\mathrm{FiO}_{2}$, fraction of inspired oxygen; HFOV, high-frequency oscillatory ventilation; $\mathrm{PaCO}_{2}$, partial pressure of carbon dioxide in arterial blood; ROC, receiver-operating curve; SEM, standard error of the mean. failed HFOV and perhaps should be considered for alternative treatment (for example, extracorporeal support).

Despite theoretical beneficial effects on minimizing lung injury and improving gas exchange, HFOV is not widely utilized because of the lack of evidence supporting a clear survival benefit over CMV [25,26,34]. Furthermore, available clinical trials do not help the clinician decide when to consider HFOV and, importantly, how long HFOV should be continued to enhance patient survival. Our study has a similar scope to the series reported by Adhikari et al. [23]; however, there are important methodological differences in the HFOV protocols and the type of recruitment maneuver (that is, a slow stepwise maneuver in our study versus a sustained inflation in Adhikari et al.) used in the two studies. Furthermore, recruitment maneuvers were performed in all patients in our case series, whereas in the study by Adhikari et al only $49.5 \%$ of the patients received a recruitment maneuver. The rationale of the stepwise recruitment we used in this study was similar to the stepwise recruitment used in neonates [35], in that it allowed for setting of the optimal CDP but it differed in two aspects. First, we used a fixed $\mathrm{FiO}_{2}$ of 1.0 and response to the recruitment was assessed as changes in $\mathrm{PaO}_{2}$. Second, in order to allow time for equilibration of $\mathrm{PaO}_{2}$ [36] and to minimize hemodynamic instability, our protocol required longer times between changes in CDP (ten minutes during the incremental phase and five minutes during the decremental phase) compared to the recruitment used in neonates [35]. It is possible that the slower and early recruitment, as performed in this study, can explain the early identification of responders to HFOV.

Although our study is not a randomized comparative study, we believe it identifies clinically important predictors of clinical outcome within the first few hours of initiation of HFOV, possibly in response to the initial SRM. Our study population included, as might be expected for a rescue study, patients with more severe ARDS than in the MOAT trial where patients received HFOV as a primary ventilation mode [26] and similar to that of the EMOAT trial [25] and the recent case series[23].

In contrast to other published reports $[17,18]$, in our study gas exchange variables $\left(\mathrm{PaO}_{2} / \mathrm{FiO}_{2}\right.$, and $\left.\mathrm{OI}\right)$ improved significantly only in survivors, and change in $\mathrm{PaO}_{2} / \mathrm{FiO}_{2}$ remained significantly different between the two outcome groups after adjusting for baseline confounding factors. Although the CDP on HFOV was higher than the CDP on CMV, there was no difference in CDP between survivors and non-survivors. Despite similar levels of CDP, the response to HFOV within the first three hours could identify patients with a favorable outcome based on $\mathrm{PaO}_{2} / \mathrm{FiO}_{2}$ and OI. 


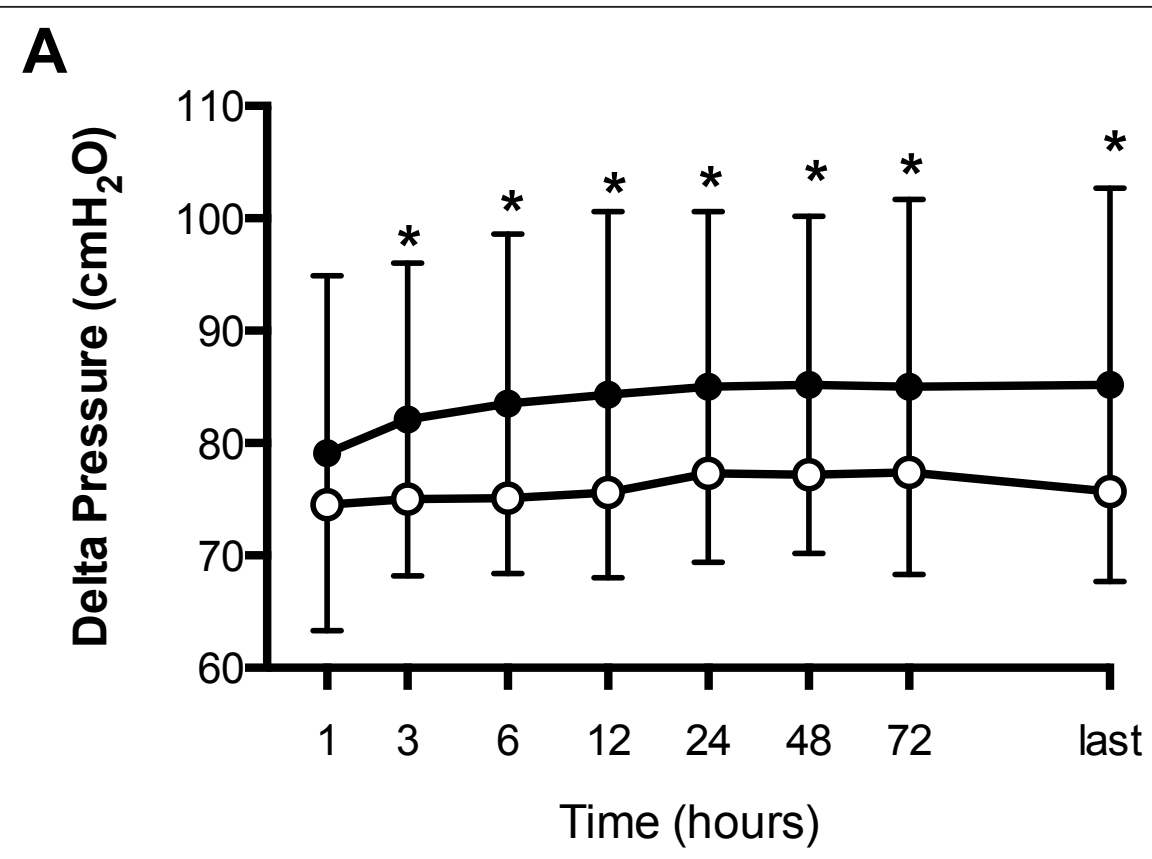

-O- Survivors

$\rightarrow$ Non-Survivors

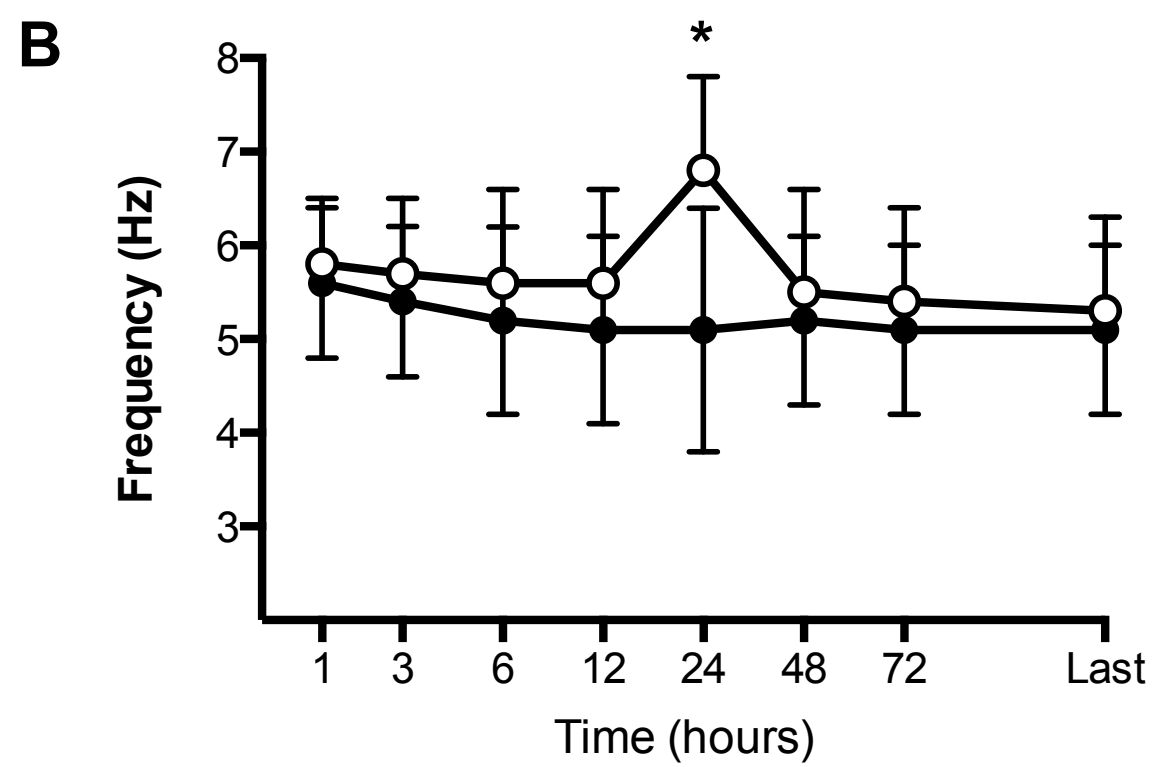

Figure 3 Differences in HFOV settings over time between survivors and non-survivors. A: Differences in Delta pressure $(\triangle P)$ in survivors (open circles) and non-survivors (filled circles) over 72 hours of HFOV. There was a significant difference in the $\triangle P$ between the two outcome groups. Data are displayed as mean and error bars represent SD at each time-point. ${ }^{*}=P<0.01$ between the two groups. B: Differences in frequency in survivors (open circles) and non-survivors (filled circles) over 72 hours of HFOV. There was a significant difference in the frequency between the two outcome groups at 24 hours. Data are displayed as mean and error bars represent SD at each time-point. ${ }^{*}=P<0.01$ between the two groups. HFOV, high-frequency oscillatory ventilation. 
An important factor for the response to HFOV may be played by the proportion of patients with pulmonary versus extra-pulmonary ARDS. Indeed, in this study we show that the largest change in $\mathrm{PaO}_{2} / \mathrm{FiO}_{2}$ post $\mathrm{HFOV}$ was seen for extra-pulmonary ARDS whereas little difference in $\mathrm{PaO}_{2} / \mathrm{FiO}_{2}$ was seen in pulmonary ARDS. This is consistent with the findings reported by Pachl et al. that show that oxygenation and recruitment during HFOV are more pronounced in patients with extra-pulmonary ARDS [37]. However, Pachl et al. studied changes in oxygenation under normocapnic conditions; therefore, no data on the different behavior of $\mathrm{PaCO}_{2}$ in the two types of ARDS are available for comparison with our data. The other important finding of our study is the effect of HFOV on $\mathrm{PaCO}_{2}$. In our study, in contrast to other reports $[19,26]$, the $\mathrm{PaCO}_{2}$ decreased significantly throughout the duration of HFOV in parallel to an increase in $\mathrm{PaO}_{2} / \mathrm{FiO}_{2}$ despite similar settings of frequency, power and amplitude. We found that in survivors there was both an increase in $\mathrm{PaO}_{2} / \mathrm{FiO}_{2}$ and a decrease in $\mathrm{PaCO}_{2}$. In addition, patients who had at least a $38 \%$ increase in their $\mathrm{PaO}_{2 /} / \mathrm{FiO}_{2}$ (as identified by the ROC curve), also showed greater reductions in $\mathrm{PaCO}_{2}$ allowing for a reduction in delta pressure. Patients with a greater disease severity (higher $\mathrm{PaCO}_{2}$, lower compliance and worse gas exchange), showed a higher rate of clearance in $\mathrm{PaCO}_{2}$ during the first six hours of HFOV. These changes in physiological variables have been described in patients with severe ARDS and higher potential for lung recruitment [38].

The increase in intra-thoracic pressure generated during a SRM could have caused a reduction in cardiac output and pulmonary blood flow, leading to a decrease in venous admixture and to an apparent improvement in $\mathrm{PaO}_{2} / \mathrm{FiO}_{2}$ in the absence of true alveolar recruitment $[39,40]$. However, this mechanism seems less likely as an explanation for the changes seen in our study, as the cardiac output and oxygen delivery were unchanged following the SRM, and therefore the combined improvement in $\mathrm{PaO}_{2} / \mathrm{FiO}_{2}$ and $\mathrm{PaCO}_{2}$ leads us to speculate that HFOV facilitated lung recruitment in a manner similar to that described for patients responding to prone positioning [41].

The 30-day mortality in this study was 56\%, comparable to the mortality rate reported in other uncontrolled studies (61.7\% [23,42], 66\% [18], 53\% [17]) but higher than the studies using HFOV as primary intervention (43\% [25] and 37\% [26]) and studies of trauma patients [16]. Multivariate analysis shows that changes in $\mathrm{PaO}_{2} /$ $\mathrm{FiO}_{2}$, age, days with ARDS prior to HFOV and baseline $\mathrm{pH}$ are independent predictive factors of mortality. Lung injury is positively associated with duration of mechanical ventilation in both animal and human studies: increased lung injury is associated with reduced likelihood of pulmonary recruitment

\section{Conclusions}

In conclusion, this study shows that HFOV is effective in improving oxygenation in some adults with ARDS, particularly when instituted early. This study also shows that changes in $\mathrm{PaO}_{2} / \mathrm{FiO}_{2}$ are sensitive criteria to predict survival and the change in $\mathrm{PaCO}_{2}$ may identify patients with a greater proportion of recruitable lung more likely to benefit from HFOV. Patients who do not show improvement in $\mathrm{PaO}_{2} / \mathrm{FiO}_{2}$ ratio and oxygenation index within six hours on commencing HFOV should be considered for extracorporeal support. These data are of potential value in aiding decision making.

Further randomized controlled trials powered to detect a difference in survival between HFOV strategies are expected. Interpretation of these comparisons will also need to take into consideration the number, the duration, and the type of recruitment maneuvers carried out during HFOV and CMV (for example, slow stepwise RMs, as employed in this study versus traditional RMs, with continuous positive airway pressure (CPAP) of 40 $\mathrm{cmH}_{2} \mathrm{O}$ for 40 seconds). The identification of patients likely to benefit from HFOV and the identification of physiological variables associated with the potential for lung recruitment will prove essential to ensure the best use of HFOV in adults with ARDS.

\section{Key messages}

- Changes in $\mathrm{PaO}_{2} / \mathrm{FiO}_{2}$ early during HFOV are sensitive criteria to predict survival.

- Patients who do not show improvement in the $\mathrm{PaO}_{2} / \mathrm{FiO}_{2}$ ratio and OI within three hours should be considered for alternative treatment (for example, extracorporeal support).

- The identification of patients likely to benefit from HFOV and the identification of physiological variables associated with the potential for lung recruitment will prove essential to ensure the best use of HFOV in adults with ARDS.

\section{Abbreviations}

ANOVA: analysis of variance; APACHE II: Acute Physiology And Chronic Health Evaluation; ARDS: Acute Respiratory Distress Syndrome; CDP: continuous distending pressure; CMV: conventional mechanical ventilation; CPAP: continuous positive airway pressure; CO: cardiac output; $\triangle \mathrm{P}$ : delta pressure; $\mathrm{FiO}_{2}$ : fraction of inspired oxygen; HFOV: high frequency oscillatory ventilation; LR: likelihood ratio; MAP: mean arterial pressure; MARS: Molecular Adsorbents Recirculation System; Ol: oxygenation index; $\mathrm{PaO}_{2}$ : partial pressure of oxygen In arterial blood; $\mathrm{PaCO}_{2}$ : partial pressure of carbon dioxide in arterial blood; PAWP: pulmonary artery wedge pressure; PEEP: positive end expiratory pressure; PIP: peak inspiratory pressure; rhAPC: recombinant human activated protein C (Drotrecogin Alfa Activated); RM: recruitment maneuver; ROC: receiver-operating characteristic; SRM: slow recruitment maneuver. 


\section{Authors' contributions}

LC designed the study, performed the statistical analysis and drafted the manuscript. TS participated in data collection. JS participated in the design of the study, data collection, and data analysis. $\mathrm{KL}$ participated in the data collection and analysis. AM participated in the design of the study, data analysis and critical revisions of the draft. RB participated in the design of the study, data analysis and critical revisions of the draft. All authors read and approved the final manuscript.

\section{Competing interests}

The authors declare that they have no competing interests.

\section{Acknowledgements}

The authors wish to thank Prof. Luciano Gattinoni and Dr. Massimo Cressoni for their critical revision of the manuscript and analysis of the severity score.

Received: 1 October 2012 Revised: 8 February 2013

Accepted: 1 March 2013 Published: 4 March 2013

\section{References}

1. Grasso S, Stripoli T, Sacchi M, Trerotoli P, Staffieri F, Franchini D, De Monte $V$, Valentini $V$, Pugliese $P$, Crovace A, Driessen B, Fiore T: Inhomogeneity of lung parenchyma during the open lung strategy: a computed tomography scan study. Am J Respir Crit Care Med 2009, 180:415-423.

2. Terragni PP, Rosboch G, Tealdi A, Corno E, Menaldo E, Davini O, Gandini G, Herrmann P, Mascia L, Quintel M, Slutsky AS, Gattinoni L, Ranieri VM: Tidal hyperinflation during low tidal volume ventilation in acute respiratory distress syndrome. Am J Respir Crit Care Med 2007, 175:160-166.

3. Pillow JJ: Tidal volume, recruitment and compliance in HFOV: same principles, different frequency. Eur Respir J 2012, 40:291-293.

4. Tsuzaki K, Hales CA, Strieder DJ, Venegas JG: Regional lung mechanics and gas transport in lungs with inhomogeneous compliance. J Appl Physiol 1993, 75:206-216.

5. Bauer $\mathrm{K}$, Brucker $\mathrm{C}$ : The role of ventilation frequency in airway reopening. J Biomech 2009, 42:1108-1113.

6. Pillow JJ: High-frequency oscillatory ventilation: mechanisms of gas exchange and lung mechanics. Crit Care Med 2005, 33:S135-141.

7. van Genderingen HR, van Vught AJ, Jansen JR: Regional lung volume during high-frequency oscillatory ventilation by electrical impedance tomography. Crit Care Med 2004, 32:787-794.

8. Mulreany DG, Simon BA, Murphy KJ, Easley RB: Volumetric xenon-CT imaging of conventional and high-frequency oscillatory ventilation. Acad Radiol 2009, 16:718-725.

9. Imai Y, Kawano T, Miyasaka K, Takata M, Imai T, Okuyama K: Inflammatory chemical mediators during conventional ventilation and during high frequency oscillatory ventilation. Am J Respir Crit Care Med 1994, 150:1550-1554

10. Imai Y, Slutsky AS: High-frequency oscillatory ventilation and ventilatorinduced lung injury. Crit Care Med 2005, 33:S129-134.

11. Yoder BA, Siler-Khodr T, Winter VT, Coalson JJ: High-frequency oscillatory ventilation: effects on lung function, mechanics, and airway cytokines in the immature baboon model for neonatal chronic lung disease. Am J Respir Crit Care Med 2000, 162:1867-1876.

12. Arnold JH, Hanson JH, Toro-Figuero LO, Gutierrez J, Berens RJ, Anglin DL: Prospective, randomized comparison of high-frequency oscillatory ventilation and conventional mechanical ventilation in pediatric respiratory failure. Crit Care Med 1994, 22:1530-1539.

13. Gerstmann DR, Minton SD, Stoddard RA, Meredith KS, Monaco F, Bertrand JM, Battisti O, Langhendries JP, Francois A, Clark RH: The Provo multicenter early high-frequency oscillatory ventilation trial: improved pulmonary and clinical outcome in respiratory distress syndrome. Pediatrics 1996, 98:1044-1057.

14. Courtney SE, Durand DJ, Asselin JM, Hudak ML, Aschner JL, Shoemaker CT: High-frequency oscillatory ventilation versus conventional mechanical ventilation for very-low-birth-weight infants. N Engl J Med 2002, 347:643-652.

15. Plavka R, Kopecky P, Sebron V, Svihovec P, Zlatohlavkova B, Janus V: A prospective randomized comparison of conventional mechanical ventilation and very early high frequency oscillatory ventilation in extremely premature newborns with respiratory distress syndrome. Intensive Care Med 1999, 25:68-75.

16. Claridge JA, Hostetter RG, Lowson SM, Young JS: High-frequency oscillatory ventilation can be effective as rescue therapy for refractory acute lung dysfunction. Am Surg 1999, 65:1092-1096.

17. Fort P, Farmer C, Westerman J, Johannigman J, Beninati W, Dolan S, Derdak S: High-frequency oscillatory ventilation for adult respiratory distress syndrome-a pilot study. Crit Care Med 1997, 25:937-947.

18. Mehta S, Lapinsky SE, Hallett DC, Merker D, Groll RJ, Cooper AB, MacDonald RJ, Stewart TE: A prospective trial of high-frequency oscillation in adults with acute respiratory distress syndrome. Crit Care Med 2001, 29:1360-1369.

19. Mehta S, Granton J, MacDonald RJ, Bowman D, Matte-Martyn A, Bachman T, Smith T, Stewart TE: High-frequency oscillatory ventilation in adults: the Toronto experience. Chest 2004, 126:518-527.

20. Cartotto R, Cooper AB, Esmond JR, Gomez M, Fish JS, Smith T: Early clinical experience with high-frequency oscillatory ventilation for ARDS in adult burn patients. J Burn Care Rehabil 2001, 22:325-333.

21. Andersen FA, Guttormsen AB, Flaatten HK: High frequency oscillatory ventilation in adult patients with acute respiratory distress syndrome-a retrospective study. Acta Anaesthesiol Scand 2002, 46:1082-1088.

22. David M, Weiler N, Heinrichs W, Neumann M, Joost T, Markstaller K, Eberle $B$ : High-frequency oscillatory ventilation in adult acute respiratory distress syndrome. Intensive Care Med 2003, 29:1656-1665.

23. Adhikari NK, Bashir A, Lamontagne F, Mehta S, Ferguson ND, Zhou Q, Hand L, Czarnecka K, Cook DJ, Granton JT, Friedrich JO, Freitag A, Watpool I, Meade MO: High-frequency oscillation in adults: a utilization review. Crit Care Med 2011, 39:2631-2644

24. Sud S, Sud M, Friedrich JO, Meade MO, Ferguson ND, Wunsch $H$, Adhikari NK: High frequency oscillation in patients with acute lung injury and acute respiratory distress syndrome (ARDS): systematic review and meta-analysis. BMJ 2010, 340:c2327.

25. Bollen CW, van Well GT, Sherry T, Beale RJ, Shah S, Findlay G, Monchi M, Chiche JD, Weiler N, Uiterwaal CS, van Vught AJ: High frequency oscillatory ventilation compared with conventional mechanical ventilation in adult respiratory distress syndrome: a randomized controlled trial [ISRCTN24242669]. Crit Care 2005, 9:R430-439.

26. Derdak S, Mehta S, Stewart TE, Smith T, Rogers M, Buchman TG, Carlin B, Lowson S, Granton J: High-frequency oscillatory ventilation for acute respiratory distress syndrome in adults: a randomized, controlled trial. Am J Respir Crit Care Med 2002, 166:801-808.

27. OSCAR Trial. 2013 [http://www.oscar-trial.org], Accessed 4 January.

28. OSCILLATE Trial. 2013 [http://www.oscillatetrial.com], Accessed 4 January.

29. Murray JF, Matthay MA, Luce JM, Flick MR: An expanded definition of the adult respiratory distress syndrome. Am Rev Respir Dis 1988, 138:720-723.

30. Lou JN, Mili N, Decrind C, Donati Y, Kossodo S, Spiliopoulos A, Ricou B, Suter PM, Morel DR, Morel P, Grau GE: An improved method for isolation of microvascular endothelial cells from normal and inflamed human lung. In Vitro Cell Dev Biol Anim 1998, 34:529-536.

31. Ventilation with lower tidal volumes as compared with traditional tidal volumes for acute lung injury and the acute respiratory distress syndrome. The Acute Respiratory Distress Syndrome Network. N Engl Med 2000, 342:1301-1308.

32. Amato MB, Barbas CS, Medeiros DM, Magaldi RB, Schettino GP, LorenziFilho G, Kairalla RA, Deheinzelin D, Munoz C, Oliveira R, Takagaki TY, Carvalho CR: Effect of a protective-ventilation strategy on mortality in the acute respiratory distress syndrome. N Engl J Med 1998, 338:347-354.

33. CareFusion C: $3100 A^{\oplus}$ High frequency oscillatory ventilator - Operator's manual. 1991, CareFusion 22745 Savi Ranch Parkway, Yorba Linda, CA 92887-4668.

34. Derdak S: High-frequency oscillatory ventilation for acute respiratory distress syndrome in adult patients. Crit Care Med 2003, 31:5317-323.

35. De Jaegere $A$, van Veenendaal MB, Michiels A, van Kaam AH: Lung recruitment using oxygenation during open lung high-frequency ventilation in preterm infants. Am J Respir Crit Care Med 2006, 174:639-645.

36. Tugrul S, Cakar N, Akinci O, Ozcan PE, Disci R, Esen F, Telci L, Akpir K: Time required for equilibration of arterial oxygen pressure after setting optimal positive end-expiratory pressure in acute respiratory distress syndrome. Crit Care Med 2005, 33:995-1000.

37. Pachl J, Roubik K, Waldauf P, Fric M, Zabrodsky V: Normocapnic highfrequency oscillatory ventilation affects differently extrapulmonary and 
pulmonary forms of acute respiratory distress syndrome in adults. Physiol Res 2006, 55:15-24.

38. Gattinoni L, Caironi P, Cressoni M, Chiumello D, Ranieri VM, Quintel M, Russo S, Patroniti N, Cornejo R, Bugedo G: Lung recruitment in patients with the acute respiratory distress syndrome. N Engl J Med 2006, 354:1775-1786.

39. Takala J: Hypoxemia due to increased venous admixture: influence of cardiac output on oxygenation. Intensive Care Med 2007, 33:908-911.

40. Dantzker DR, Lynch JP, Weg JG: Depression of cardiac output is a mechanism of shunt reduction in the therapy of acute respiratory failure. Chest 1980, 77:636-642.

41. Gattinoni L, Vagginelli F, Carlesso E, Taccone P, Conte V, Chiumello D, Valenza F, Caironi P, Pesenti A: Decrease in $\mathrm{PaCO} 2$ with prone position is predictive of improved outcome in acute respiratory distress syndrome. Crit Care Med 2003, 31:2727-2733.

42. Ferguson ND, Kacmarek RM, Chiche JD, Singh JM, Hallett DC, Mehta S, Stewart TE: Screening of ARDS patients using standardized ventilator settings: influence on enrollment in a clinical trial. Intensive Care Med 2004, 30:1111-1116.

doi:10.1186/cc12550

Cite this article as: Camporota et al:: Physiological predictors of survival during high-frequency oscillatory ventilation in adults with acute respiratory distress syndrome. Critical Care 2013 17:R40.

\section{Submit your next manuscript to BioMed Central} and take full advantage of:

- Convenient online submission

- Thorough peer review

- No space constraints or color figure charges

- Immediate publication on acceptance

- Inclusion in PubMed, CAS, Scopus and Google Scholar

- Research which is freely available for redistribution

Submit your manuscript at www.biomedcentral.com/submit
C Biomed Central 